\title{
Inherited duplication of the pseudoautosomal region Xq28 in a subject with Gilles de la Tourette syndrome and intellectual disability: a case report
}

Stefania Maccarini ${ }^{1}$, Annamaria Cipani ${ }^{2}$, Valeria Bertini ${ }^{1}$, Jelena Skripac ${ }^{1}$, Alessandro Salvi ${ }^{1}$, Giuseppe Borsani ${ }^{1}$ and Eleonora Marchina ${ }^{1 *}$ (D)

\begin{abstract}
Background: Tourette syndrome (TS) is a complex neurodevelopmental disorder (NDD) characterized by multiple chronic involuntary motor and vocal tics with onset during childhood or adolescence. Most TS patients present with additional comorbidities, typically attention deficit hyperactivity disorder (ADHD), obsessive- compulsive disorder (OCD), autism spectrum disorder (ASD) and intellectual disability (ID). Both TS and ID are genetically complex disorders that likely occur as a result of the effects of multiple genes interacting with other environmental factors. In addition to single gene mutations and chromosomal disorders, copy number variations (CNVs) are implicated across many NDDs and ID and contribute to their shared genetic etiology. Screening of CNVs using microarray-based Comparative Genomic Hybridization (aCGH) is now routinely performed in all subjects with NDD and ID.

Case presentation: We report a case of a 12-year-old girl diagnosed with Gilles de la Tourette Syndrome associated to behavior disorders and intellectual disability in particular with regard to language. Array-CGH analysis showed a CNV of a subtelomeric region Xq28 (gain of $260 \mathrm{~kb}$ ) inherited from the healthy father. The duplication contains two genes, VAMP7 and SPRY3 of the PAR2 pseudoautosomal region. FISH analysis revealed that the duplicated segment is located on the short arm of a chromosome 13, resulting in a trisomy of the region. In the proband the expression levels of the genes evaluated in the peripheral blood sample are comparable both those of the mother and to those of female control subjects.

(Continued on next page)
\end{abstract}

\footnotetext{
* Correspondence: eleonora.marchina@unibs.it

'Division of Biology and Genetics, Department of Molecular and Translational Medicine, University of Brescia, Brescia, Italy

Full list of author information is available at the end of the article
}

(c) The Author(s). 2020 Open Access This article is licensed under a Creative Commons Attribution 4.0 International License, which permits use, sharing, adaptation, distribution and reproduction in any medium or format, as long as you give appropriate credit to the original author(s) and the source, provide a link to the Creative Commons licence, and indicate if changes were made. The images or other third party material in this article are included in the article's Creative Commons licence, unless indicated otherwise in a credit line to the material. If material is not included in the article's Creative Commons licence and your intended use is not permitted by statutory regulation or exceeds the permitted use, you will need to obtain permission directly from the copyright holder. To view a copy of this licence, visit http://creativecommons.org/licenses/by/4.0/. The Creative Commons Public Domain Dedication waiver (http://creativecommons.org/publicdomain/zero/1.0/) applies to the data made available in this article, unless otherwise stated in a credit line to the data. 


\begin{abstract}
(Continued from previous page)
Conclusions: Although the trisomy of the $260 \mathrm{~kb}$ region from Xq28 identified in proband is also shared by the healthy father, it is tantalizing to speculate that, together with genetic risk factors inherited from the mother, it may play a role in the development of a form of Tourette syndrome with intellectual disability. This hypothesis is also supported by the fact that both genes present in the duplicated region (VAMP7 and SPRY3) are expressed in the CNS and are implicated in neurotransmission and neurite growth and branching. In addition, similar CNVs have been identified in individuals whose phenotype is associated with autism spectrum disorders or intellectual disability.
\end{abstract}

Keywords: Xq28 trisomy, CNVs, Array-CGH, PAR2, Gilles de la Tourette syndrome, Intellectual disability

\section{Background}

Gilles de la Tourette Syndrome (TS; OMIM \#137580) is a childhood-onset neurodevelopmental disorder characterized by the presence of motor and vocal tics. Most patients show improvement at the end of adolescence, but symptoms can persist into adulthood in about a third of cases [1]. The prevalence estimates range from 0.3 to $0.9 \%$ [2], with males more frequently affected than females with a ratio of 3:1.

In TS patients co-morbidities are frequent. Among them attention deficit hyperactivity disorder (ADHD), obsessive-compulsive disorder (OCD) [3], learning disorders (LD) [4]. Autism spectrum disorders (ASD), other behavioral and psychosocial problems like anxiety, selfinjurious behavior, oppositional defiant and conduct disorders [5] may also be present (reviewed in [4, 6]).

TS as well as ID are genetically complex disorders that likely occur as a result of the effects of multiple genes interacting with other environmental factors. In addition to single gene mutations and chromosomal disorders, copy number variations (CNVs) are implicated across many NDDs and ID and contribute to their shared genetic etiology [7, 8]. Screening of CNVs using aCGH is now routinely performed in all subjects with NDD and ID.

Although previous family studies suggested an autosomal dominant pattern of inheritance, more recent analysis suggest that the mode of inheritance of Tourette Syndrome is more complex. TS heritability is estimated to be 0,77 making it one of the most heritable complex neuropsychiatric disorders [9]. Despite such a strong genetic component, the identification of TS susceptibility genes has proven challenging so far. Although linkage analyses have identified several candidate regions, there is little consensus across studies, suggesting that, as with other neuro-psychiatric disorders, TS is genetically complex and heterogeneous [10].

A limited number of Genome-Wide Association Studies (GWAS) of TS has been published to date either reaching a marginal genome-wide significance or failing to identify genome-wide significant loci for the disease [11]. Mutations involving the SLITRK1 gene have been identified in a small number of people with Tourette syndrome [12]. SLITKR1 is highly expressed in the central nervous system and plays a critical part in regulating synapse formation between hippocampal neurons and in differentiation of synapses, helping in neuronal outgrowth. However, most people with Tourette syndrome do not have a mutation in the SLITRK1 gene.

The impact of rare CNVs on TS disease risk has been assessed in a large sample of $>6500$ unrelated individuals of European ancestry. The study demonstrated a global increase in the burden of large, rare CNVs in TS cases compared to controls driven primarily by large, singleton events, in particular large $(>1 \mathrm{Mb})$ deletions, consistent with marked genetic heterogeneity. The authors also identified two TS susceptibility loci: deletions in NRXN1 and duplications in CNTN6 genes, each conferring a substantial increase in disease risk (together are present in $1 \%$ of TS cases).

NRXN1 encodes a presynaptic cell-adhesion molecule involved in synaptogenesis and synaptic transmission at both glutamatergic and GABAergic synapses [13]. Heterozygous mutations of the NRXN1 gene have been also repeatedly associated with autism and schizophrenia.

Like NRXN1, CNTN6 encodes a cell-adhesion molecule expressed primarily in the CNS that play a role in the formation of axon connections in the developing nervous system [14]. Interestingly, a de novo duplication of the CNTN6 gene was identified in an autistic patient [15]. As in other complex neuropsychiatric disorders, although there may be a few genes with substantial effects, it is likely that Tourette Syndrome risk involves a combination of common, low-effect and rare, larger-effect variants in multiple genes acting together with environmental factors [16]. Here we report the case of a 12year-old girl diagnosed with TS associated to ID showing a CNV in Xq28 (duplication of $260 \mathrm{~kb}$ ) in the subtelomeric region, inherited from the father, that results in a trisomy for the region involved.

\section{Case presentation}

The proband, a 12 and a half years old female, is the only daughter of healthy and non-consanguineous Caucasian parents (the mother is 36 years old, the father 40 
at conception). She was delivered by cesarean section for maternal reasons at 39 weeks of a spontaneous and unremarkable pregnancy. Amniocentesis was performed due to advanced maternal age resulting in a normal female karyotype $(46, \mathrm{XX})$. The birth weight was $3000 \mathrm{~g}$ (25th percentile), length $50 \mathrm{~cm}$ (50th percentile), head circumference $35 \mathrm{~cm}$ (50th percentile), Apgar score was 8 and 10 at 1 and 5 min respectively. After birth she was referred as normal: she was breastfed for a few weeks, then artificially, weaned at 6 months. She walked independently at one year, spoke the first words at 18 months. At the admission to the kindergarten, at the age of 3, she was referred to the Child Neuropsychiatry Unit on account of language impairment. Intensive speech therapy was supplied for 2 years, then continued with less frequent sessions during the primary school with slowly but steadily positive results. During the second year of the primary school, at the age of 7 , learning disability and behavioral disorders became evident. Cognitive assessment performed by Leiter $\mathrm{R}$ scale (specific for nonverbal intelligence) and by WPPSI-III, gave an IQ of 91 and 77, respectively (with VIQ $=68$, PIQ $=89$ at the latter scale). A diagnosis of a neurodevelopmental disorder compatible with Gilles de la Tourette syndrome was made at age of 11 for the presence of motor and vocal tics, hyperactivity, motor and behavioral mannerisms, together with mild intellectual disability. During instrumental work up audiological examination, EEG and brain MRI were performed with normal results. At the last follow-up, when she was 12 years old, physical examination showed a height of $153 \mathrm{~cm}$ (35th percentile), weight of $61 \mathrm{~kg}$ (91th percentile). She had her first menstruation at the age of 11 years without dysmenorrhea or other related problems. Motor embarrassment and bilateral flat foot, corrected with orthotics, were persistent. The last cognitive assessment performed in 2015 by Leiter R gave an IQ score of 69 , with WISC IV scale the results indicated total IQ of $57(\mathrm{VCI}=60, \mathrm{PRI}=67$, WMI $=61$, PSI $=85$ ) while the GAI was 59. The proband now attends the second class of the secondary school

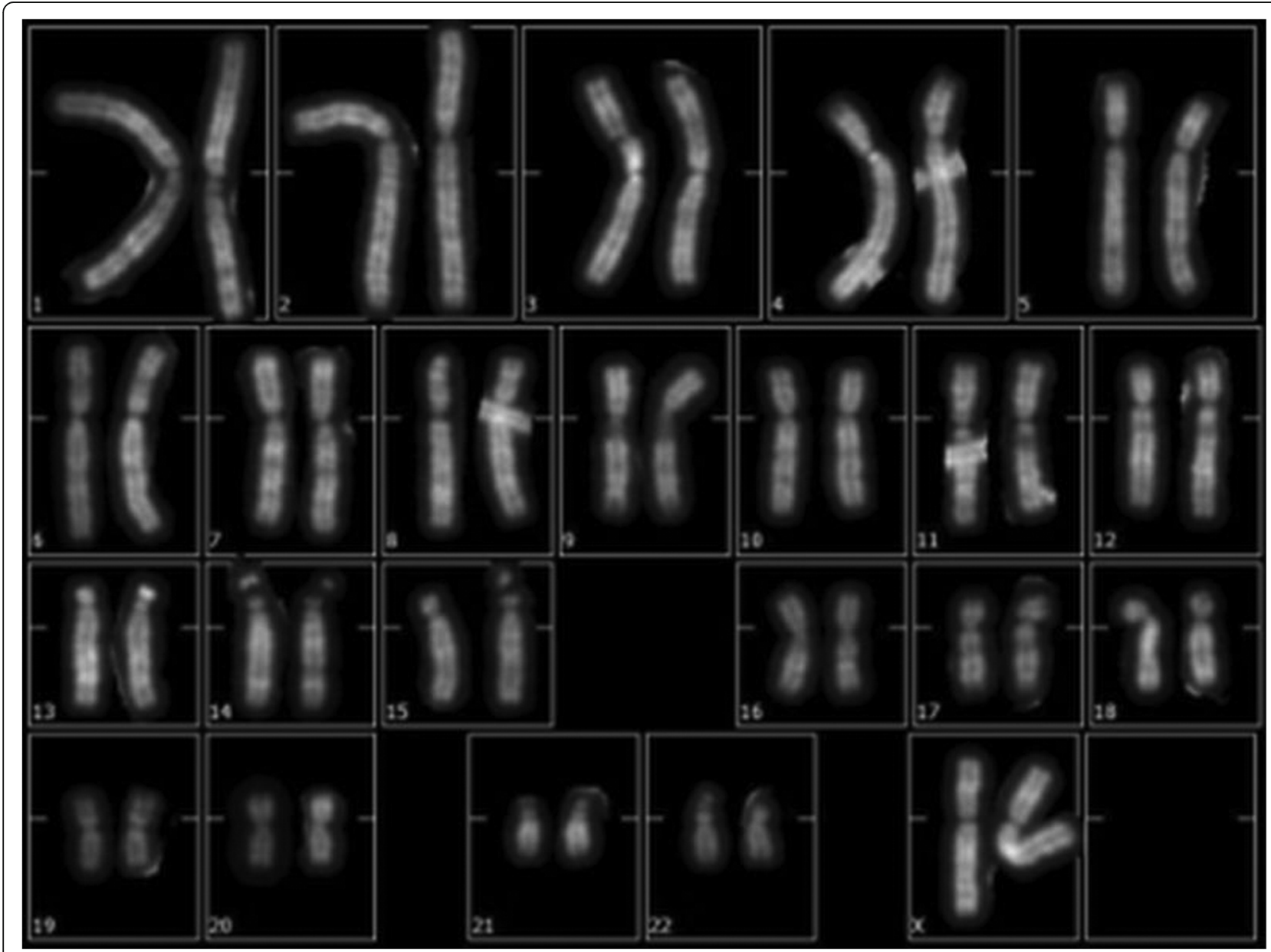

Fig. 1 Metaphase of peripheral blood of the proband showing normal chromosome contents with QFQ banding. Cytogenetic analysis was performed using Q-banding at 550 bands resolution, in line with the International System for Human Cytogenetic Nomenclature (ISCN, 2016) 


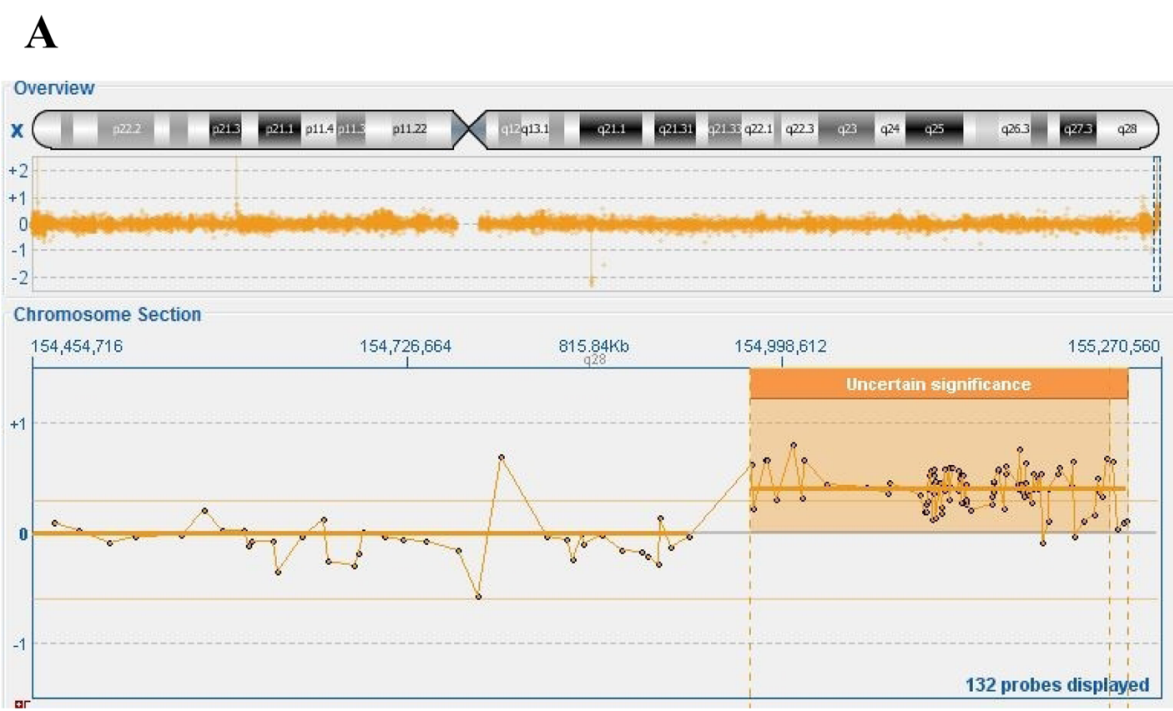

B

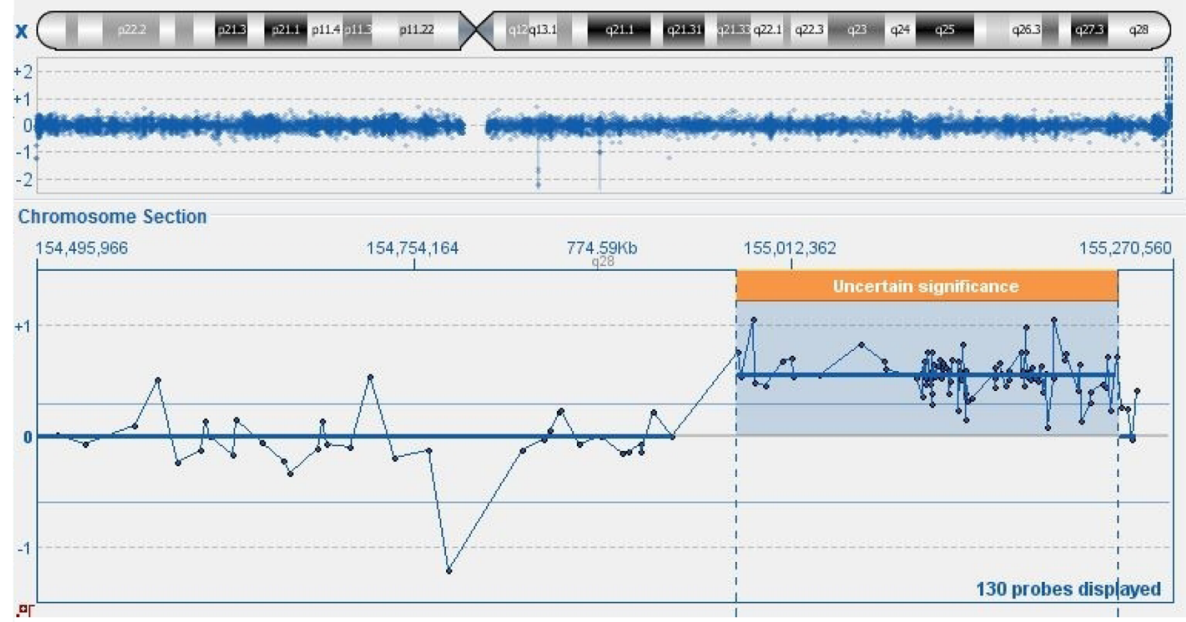

Fig. 2 Array-CGH analysis of the proband (a) and of the father (b) showing a copy number variation of $260 \mathrm{~kb}$ of the terminal region of chromosome X. aCGH was performed using the Oxford Gene Technologies CytoSure ISCA v.2 4x180K Microarray Kit (backbone resolution: 1 probe every $25 \mathrm{~kb}$ ) according to the manifacturer's recommendations. Promega G152A and 147A were used as female and male reference DNA, respectively. Analysis of aCGH data was performed using the CytoSure Interpret Software (Oxford Gene Technologies). The X chromosome coordinates are relative to the GRCh37/hg19 assembly

with a learning support teacher. Pharmacological treatment with Aripiprazole $8 \mathrm{mg} /$ day is ongoing.

\section{Results}

Karyotype analysis was performed on peripheral blood lymphocytes of the proband stimulated with phytohaemoagglutinin. The 20 metaphases analyzed by highresolution QFQ banding (550 bands) revealed normal female karyotype 46,XX (Fig. 1). FRAXA analysis performed by PCR on DNA from peripheral blood revealed that the proband is heterozygous for two FMR1 alleles with a number of CGG triplets in the normal range (29/
$30+/-1)$ (data not shown). This result allowed to exclude that the patient is affected by the fragile X Syndrome. Array-CGH analysis, performed using the Oxford Gene Technology 4x180K platform, revealed a copy gain of a $260 \mathrm{~kb}$ region in Xq28, at the terminal region of the long arm the $\mathrm{X}$ chromosome (Fig. 2A). This region includes the complete sequence of the $S P R Y 3$ and VAMP7 (also known as SYBL1) genes and a portion at the $5^{\prime}$ side of the $I L 9 R$ gene, within the PAR2 pseudoautosomal region. Array-CGH analysis performed on the parents revealed that the terminal Xq28 duplication was inherited from the father (Fig. 2B), while the mother did not present this CNV. 
A

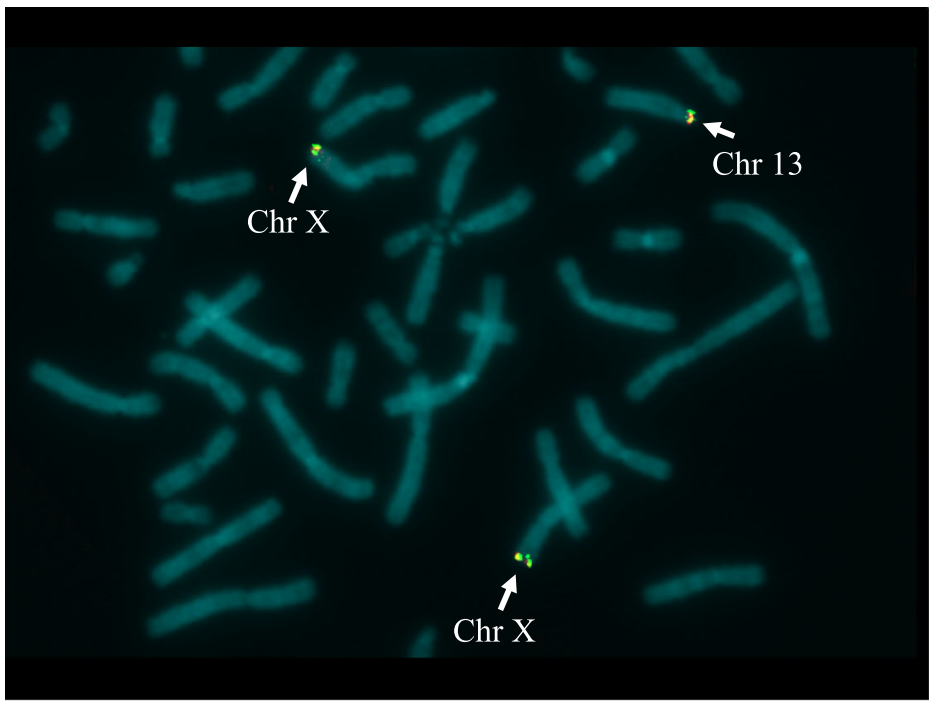

B

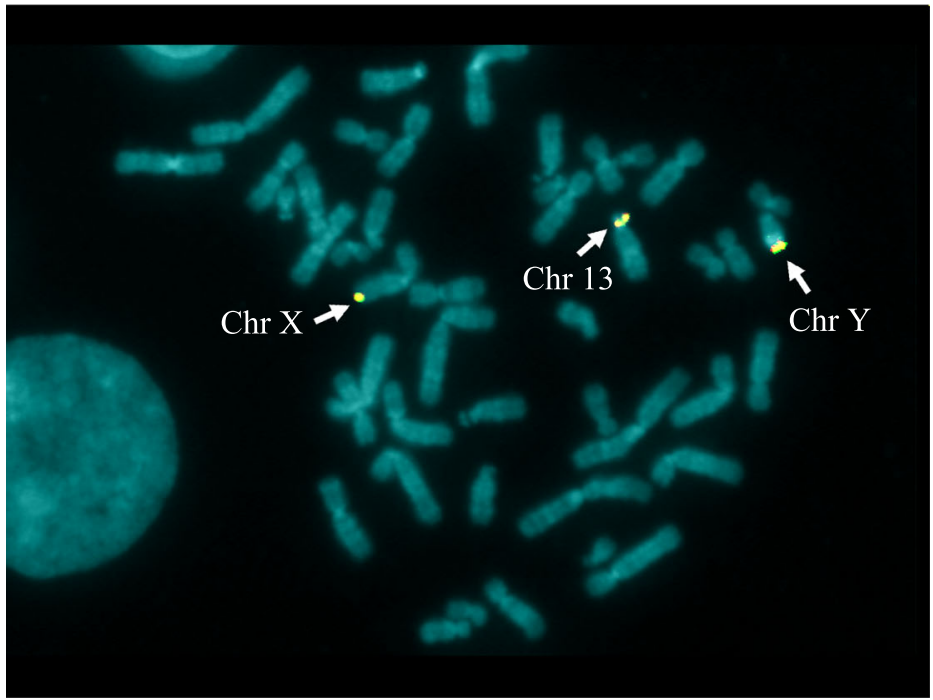

Fig. 3 FISH analysis of the proband (a) and of the father (b) with a probe for the subtelomeric region of chromosome X. FISH analysis was carried out on metaphase chromosomes using the subtelomeric probe (Vysis TelVysion DNA Probes) Xqter (EST Cdy 16c07, GenBank Z43206)

To confirm the duplication and locate its position, FISH was performed on a smear of peripheral blood lymphocytes of the proband using a subtelomeric probe of long arm of chromosome $\mathrm{X}$, which includes the VAMP7 gene (EST Cdy 16c07, GenBank Z43206). FISH analysis shows the presence of a hybridization signal in the subtelomeric region of both $\mathrm{X}$ chromosomes plus an additional one on the short arm of a chromosome 13 in p13, confirming the trisomy of the Xq28 region (Fig. 3A).

The final karyotype, expressed in GRCh37/hg19 coordinates, therefore appears to be: 46,XX.arr[GRCh37] Xq28(154974696_155232894)×3.ish $\operatorname{der}(13) t(X ; 13)$ (q28; p13)(EST CdY 16c07 for VAMP7+). FISH analysis performed on the father with the same probe used for the proband, shows a result identical to that of the daughter
(Fig. 3B). In the specific case the hybridization signals of the $\mathrm{Xq}$ subtelomeric probe were present on the $\mathrm{X}$ chromosome and on the $\mathrm{Y}$ chromosome (being the pseudoautosomal region) and on the short arm of the chromosome 13. This also results in a trisomy of the region of interest. Although it is tantalizing to hypothesize that the neurodevelopmental phenotype of the proband is due to the trisomy of the $260 \mathrm{~kb} \mathrm{Xq} 28$ region, the same chromosomal imbalance is present in the healthy father. To ascertain if the father is a mosaic for the observed mutation, thus justifying his normal phenotype, a new FISH analysis was performed with the same probe on a larger number of metaphases. All the 100 metaphases analyzed show the presence of the derivative chromosome 13, thus excluding the occurrence of mosaicism, at least in peripheral blood cells. The $260 \mathrm{~kb}$ 


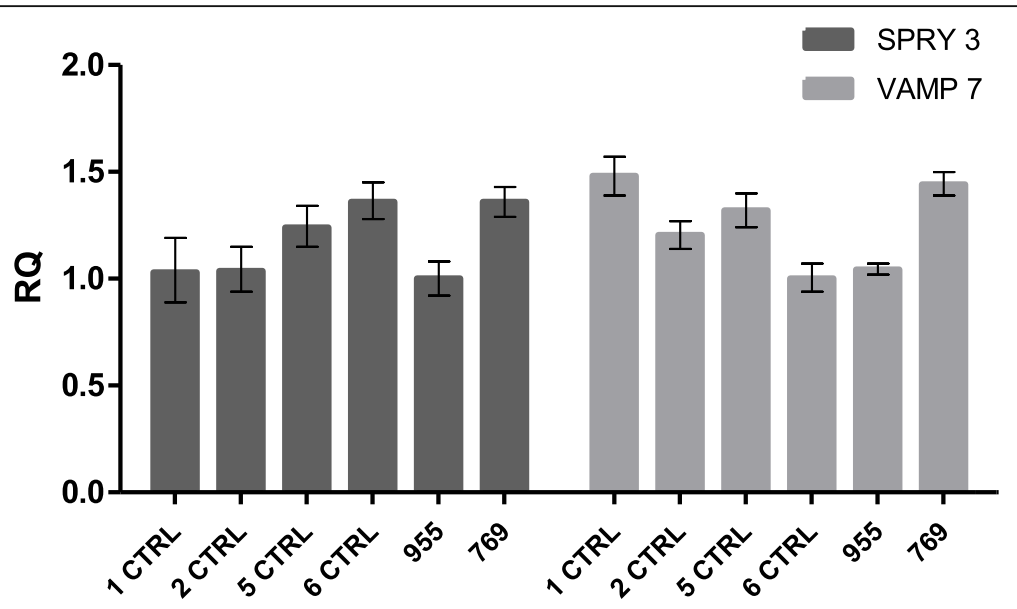

Fig. 4 Relative quantification (RQ) of the expression of SPRY3 (dark grey bars) and VAMP7 (light grey bars) genes in blood RNA evaluated by qRTPCR in female control subjects (1-6 CTRL), in the proband (769) and in her mother (955). Unfortunately, the father of the proband was not available to be tested. qRT-PCR was carried out using TaqMan Gene Expression assays for the two genes on RNA from the peripheral blood obtained with the PAXgene Blood RNA Kit (Qiagen)

triplicated region is included in pseudoautosomal region PAR2 and contains the entire sequence of VAMP7 and SPRY3 genes. qRT-PCR was carried out using TaqMan Gene Expression assays for VAMP7 and SPRY3 genes on total RNA from the peripheral blood using the PAX gene Blood RNA kit (Qiagen). The experiment provides no evidence that the expression level of the two genes is altered with respect to that of the mother and of normal female controls (Fig. 4).

\section{Discussion and conclusions}

This study describes the case of a 12 years old girl presenting Tourette Syndrome and intellectual disability in particular with regard to language with a $\mathrm{CNV}$ in Xq28 (duplication of $260 \mathrm{~kb}$ ) in the subtelomeric region, inherited from the healthy father, that results in a trisomy for the region involved. The duplication is fully included in the PAR2 region. The pseudoautosomal regions get their name because any genes within them are inherited like any autosomal genes. PAR1 comprises $2.6 \mathrm{Mb}$ of the short-arm tips of both $\mathrm{X}$ and $\mathrm{Y}$ chromosomes in humans while PAR2 is at the tips of the long arms, spanning $320 \mathrm{~kb}$. According to the HUGO Gene Nomenclature Committee (HGNC) the PAR2 region contains 4 protein coding genes (DDX11L16, IL9R, SPRY3 and VAMP7), 5 pseudogenes and 1 gene for a long noncoding anstisense RNA. The two protein coding genes included in the region duplicated in the proband, SPRY3 and VAMP7, undergo $\mathrm{X}$-inactivation and the $\mathrm{Y}$ alleles in males are also silent $[17,18]$.

The VAMP7 (vesicle-associated membrane protein 7 gene) gene encodes a member of the synaptobrevin family of proteins involved in synaptic vesicle docking,

Table 1 Duplications involving the VAMP7, SPRY3 and IL9R genes, highlighted alone or together with other CNVs in the same patient as reported in the Decipher database. The phenotype highlighted in each case, the size of the CNV and its classification/ interpretation is also reported

\begin{tabular}{llllll}
\hline Decipher $\mathrm{n}$. & CNV size & Genes involved & Phenotype & N. of CNV & Classification \\
\hline 283,573 & $289,76 \mathrm{~Kb}$ & VAMP7-SPRY3-IL9R & Anomalies of the nervous system & 4 & Unknown \\
287,906 & $272,18 \mathrm{~Kb}$ & VAMP7-SPRY3-IL9R & Intellectual disability & 4 & Likely benign \\
295,447 & $204,25 \mathrm{~Kb}$ & VAMP7-SPRY3 & Autism & 1 & Unknown \\
289,826 & $224,04 \mathrm{~Kb}$ & VAMP7-SPRY3 & Intellectual disability & 4 & Likely benign (maternal) \\
288,136 & $258,43 \mathrm{~Kb}$ & VAMP7-SPRY3-IL9R & Intellectual disability & 4 & Unknown \\
266,523 & $258,19 \mathrm{~Kb}$ & VAMP7-SPRY3-IL9R & Autism & 3 & Unknown \\
295,234 & $232,44 \mathrm{~Kb}$ & VAMP7-SPRY3 & Cognitive impairment & 3 & Unknown \\
287,714 & $147,3 \mathrm{~Kb}$ & VAMP7-IL9R & $?$ & 4 & Unknown (de novo) \\
341,563 & $289,99 \mathrm{~Kb}$ & VAMP7-SPRY3-IL9R & Language delay & 1 & Likely benign \\
369,986 & $213,42 \mathrm{~Kb}$ & VAMP7-SPRY3 & Intellectual disability & 3 & Unknown \\
\hline
\end{tabular}


Table 2 Duplications involving the VAMP7, SPRY3 and IL9R genes, highlighted alone or together with other CNVs in the same patient as reported in the ClinGen database. The phenotype highlighted in each case, the size of the CNV and its classification/ interpretation is also reported

\begin{tabular}{llllll}
\hline NSSV-NSV & CNV size & Genes involved & Phenotype & $N^{\circ}$ of CNV & Classification \\
\hline $581510-529342$ & $195,2 \mathrm{~Kb}$ & SYBL1-SPRY3 & Autism & 1 & unknown \\
$581511-532993$ & $305 \mathrm{~Kb}$ & SYBL1-SPRY3-IL9R & Developmental delay & 1 & unknown \\
$581512-532924$ & $285,9 \mathrm{~Kb}$ & SYBL1-SPRY3 & Developmental delay & 1 & unknown \\
$1604719-915617$ & $258,2 \mathrm{~Kb}$ & SYBL1-SPRY3-IL9R (part.) & Developmental delay & 3 & likely benign \\
$1601341-915617$ & $258,2 \mathrm{~Kb}$ & SYBL1-SPRY3-IL9R (part.) & Autism & 1 & likely benign \\
$1603110-916312$ & $115,6 \mathrm{~Kb}$ & SYBL1 (part.)-SPRY3 (part.) & Developmental delay & 1 & likely benign \\
$581513-532995$ & $185,2 \mathrm{~Kb}$ & SYBL1-SPRY3 (part.) & Behavioral anomalies & 1 & unknown \\
$1609838-931742$ & $131,4 \mathrm{~Kb}$ & SYBL1 (part.)-IL9R & Developmental delay & 1 & benign \\
\hline
\end{tabular}

exocytosis, and membrane transport. Vamp7-lacking mice have been shown to exhibit increased anxiety, indicating that VAMP7 mediated neurotransmission has an important role in higher brain functions [19]. A reduction of protein levels of VAMP7 selectively inhibit spontaneous neurotransmission both in cultured neurons and in hippocampal slices [20]. Interestingly, a polymorphism in the regulatory region of the gene has been associated with bipolar affective disorders [21, 22].

SPRY3 is a member of a family of negative regulators of Receptor Tyrosine Kinase (RTK) signaling that is involved in axonal morphogenesis [23]. The gene is highly expressed in central and peripheral nervous system ganglion cells in mouse and human, including cerebellar Purkinje cells and retinal ganglion cells. Transient overexpression or knockdown of Spry3 in cultured mouse superior cervical ganglion cells inhibits and promotes, respectively, neurite growth and branching [24]. Recent studies suggest that SPRY3 deregulation may be involved in the pathogenesis of autism [24, 25].

The $260 \mathrm{~kb}$ duplication in $\mathrm{Xq} 28$ is not reported as polymorphism in the Database of Genomic Variants (DGV), not exceeding 1\% [26]. Two cases of copy number gain involving SPRY3 and VAMP7 and are reported in the DECIPHER Database [27], which present this $\mathrm{CNV}$ as the only variant and whose phenotype is associated with autism or language delay. The duplications have a length of $204 \mathrm{~kb}$ and $290 \mathrm{~kb}$, respectively (Table 1). Unlike our case, the probands are male and the inheritance of this CNV is not known. In ClinGen [28], five cases are reported which present this $\mathrm{CNV}$ as the only variant and whose phenotype is associated with autism, developmental delay and behavioral anomalies (Table 2). Duplications vary from a minimum of $116 \mathrm{~kb}$ to a maximum of $305 \mathrm{~kb}$. The sex of these patients is not known. It is thus conceivable that the genic imbalance in the proband is involved in the pathogenesis of the phenotype. To assess a possible implication of the CNV in the patient's phenotype, a qRT-PCR analysis was carried out showing that in whole blood there is comparable expression of VAMP7 and SPRY3 genes between the proband and the mother and the investigated female controls. This is an unexpected finding, considering that the proband carry an extra copy of the two genes on the short arm of the chromosome 13 . This result may be due to a position effect, as observed in many cases of unbalanced chromosomal rearrangements [29].These data, however, do not exclude that an altered gene expression may be present in other unexplored tissue, in particular in the CNS.

The healthy father and the affected daughter present the same rearrangement: where does the phenotypic diversity between the two subjects come from? In the literature are reported several cases of subjects carrying the same chromosomal imbalance but with discordant phenotypes and this is often attributed to incomplete penetrance or variable expressiveness. We can speculate that both the $\mathrm{Xq} 28 \mathrm{CNV}$ and genetic risk factors inherited from the mother are required for the development this form of Tourette syndrome with neurodevelopmental delay.

The accurate follow up of the patient together with additional genomic analysis may provide new insights on the molecular basis of the patient's phenotype and for genetic counseling.

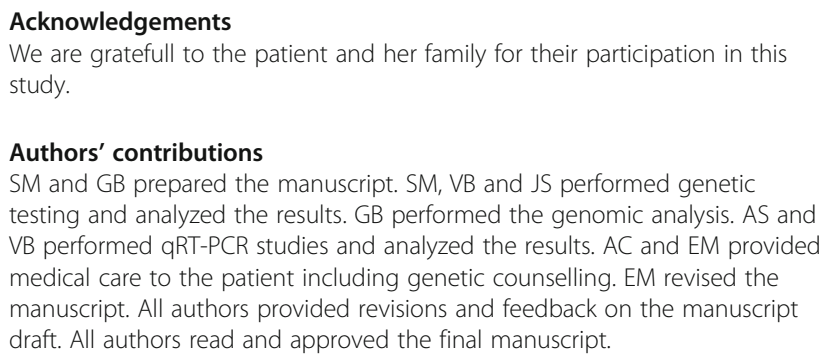

Authors' contributions

SM and GB prepared the manuscript. SM, VB and JS performed genetic testing and analyzed the results. GB performed the genomic analysis. AS and VB performed qRT-PCR studies and analyzed the results. AC and EM provided medical care to the patient including genetic counselling. EM revised the manuscript. All authors provided revisions and feedback on the manuscript draft. All authors read and approved the final manuscript.

\section{Funding}

This research received no specific grant from any funding agency.

Ethics approval and consent to participate

Not applicable. 


\section{Consent for publication}

Informed consent for analysis was obtained from patient's parents and the study protocol conforms to the Italian ethical guidelines.

\section{Competing interests}

The authors declare that they have no competing interests.

\section{Author details}

'Division of Biology and Genetics, Department of Molecular and Translational Medicine, University of Brescia, Brescia, Italy. ${ }^{2}$ Unit of Child and Adolescent Neuropsychiatry, ASST of Garda, Brescia, Italy.

Received: 18 March 2020 Accepted: 10 June 2020

Published online: 22 June 2020

\section{References}

1. Leckman JF. Tourette's syndrome. Lancet. 2002;360(9345):1577-86.

2. Scharf JM, Miller LL, Gauvin CA, Alabiso J, Mathews CA, Ben-Shlomo Y. Population prevalence of Tourette syndrome: a systematic review and meta-analysis. Mov Disord. 2015;30(2):221-8.

3. Swain JE, Scahill L, Lombroso PJ, King RA, Leckman JF. Tourette syndrome and tic disorders: a decade of progress. J Am Acad Child Adolesc Psychiatry. 2007:46(8):947-68.

4. Cravedi E, Deniau E, Giannitelli M, Xavier J, Hartmann A, Cohen D. Tourette syndrome and other neurodevelopmental disorders: a comprehensive review. Child Adolesc Psychiatry Ment Health. 2017;11:59.

5. Hirschtritt ME, Lee PC, Pauls DL, Dion Y, Grados MA, IIImann C, et al. Lifetime prevalence, age of risk, and genetic relationships of comorbid psychiatric disorders in Tourette syndrome. JAMA Psychiatry. 2015;72(4): 325-33

6. Jankovic J. Tourette syndrome: pathogenesis, clinical features and diagnosis. Waltham, MA (Accessed on November 26, 2019): UpToDate.

7. Qiao Y, Mercier E, Dastan J, Hurlburt J, McGillivray B, Chudley AE, et al. Copy number variants (CNVs) analysis in a deeply phenotyped cohort of individuals with intellectual disability (ID). BMC Med Genet. 2014;15:82.

8. Zarrei M, Burton CL, Engchuan W, Young EJ, Higginbotham EJ, MacDonald $J R$, et al. A large data resource of genomic copy number variation across neurodevelopmental disorders. NPJ Genom Med. 2019;4:26

9. Mataix-Cols D, Isomura K, Perez-Vigil A, Chang Z, Ruck C, Larsson KJ, et al. Familial risks of Tourette syndrome and chronic tic disorders. A PopulationBased Cohort Study JAMA Psychiatry. 2015;72(8):787-93.

10. Robertson MM, Eapen V, Singer HS, Martino D, Scharf JM, Paschou P, et al. Gilles de la Tourette syndrome. Nat Rev Dis Primers. 2017;3:16097.

11. Qi Y, Zheng Y, Li Z, Liu Z, Xiong L. Genetic studies of tic disorders and Tourette syndrome. Methods Mol Biol. 2011;2019:547-71.

12. Abelson JF, Kwan KY, O'Roak BJ, Baek DY, Stillman AA, Morgan TM, et al. Sequence variants in SLITRK1 are associated with Tourette's syndrome. Science. 2005;310(5746):317-20.

13. Pak C, Danko T, Zhang Y, Aoto J, Anderson G, Maxeiner S, et al. Human neuropsychiatric disease modeling using conditional deletion reveals synaptic transmission defects caused by heterozygous mutations in NRXN1. Cell Stem Cell. 2015;17(3):316-28.

14. Oguro-Ando A, Zuko A, Kleijer KTE, Burbach JPH. A current view on contactin-4, -5 , and -6 : implications in neurodevelopmental disorders. Mol Cell Neurosci. 2017:81:72-83.

15. van Daalen E, Kemner C, Verbeek NE, van der Zwaag B, Dijkhuizen T, Rump $P$, et al. Social responsiveness scale-aided analysis of the clinical impact of copy number variations in autism. Neurogenetics. 2011;12(4):315-23.

16. Qi Y, Zheng Y, Li Z, Xiong L. Progress in Genetic Studies of Tourette's Syndrome. Brain Sci. 2017;7(10)

17. De Bonis ML, Cerase A, Matarazzo MR, Ferraro M, Strazzullo M, Hansen RS, et al. Maintenance of X-and Y-inactivation of the pseudoautosomal (PAR2) gene SPRY3 is independent from DNA methylation and associated to multiple layers of epigenetic modifications. Hum Mol Genet. 2006;15(7): 1123-32.

18. Matarazzo MR, De Bonis ML, Gregory RI, Vacca M, Hansen RS, Mercadante G, et al. Allelic inactivation of the pseudoautosomal gene SYBL1 is controlled by epigenetic mechanisms common to the $X$ and $Y$ chromosomes. Hum Mol Genet. 2002;11(25):3191-8.
19. Danglot L, Zylbersztejn K, Petkovic M, Gauberti M, Meziane H, Combe R, et al. Absence of TI-VAMPNamp7 leads to increased anxiety in mice. J Neurosci. 2012;32(6):1962-8.

20. Crawford DC, Ramirez DM, Trauterman B, Monteggia LM, Kavalali ET. Selective molecular impairment of spontaneous neurotransmission modulates synaptic efficacy. Nat Commun. 2017;8:14436.

21. Saito T, Parsia S, Papolos DF, Lachman HM. Analysis of the pseudoautosomal X-linked gene SYBL1 in bipolar affective disorder: description of a new candidate allele for psychiatric disorders. Am J Med Genet. 2000;96(3):317-23.

22. Muller DJ, Schulze TG, Jahnes E, Cichon S, Krauss H, Kesper K, et al. Association between a polymorphism in the pseudoautosomal X-linked gene SYBL1 and bipolar affective disorder. Am J Med Genet. 2002;114(1):748.

23. Panagiotaki N, Dajas-Bailador F, Amaya E, Papalopulu N, Dorey K Characterisation of a new regulator of BDNF signalling, Sprouty3, involved in axonal morphogenesis in vivo. Development. 2010;137(23):4005-15.

24. Ning Z, McLellan AS, Ball M, Wynne F, O'Neill C, Mills W, et al. Regulation of SPRY3 by $X$ chromosome and PAR2-linked promoters in an autism susceptibility region. Hum Mol Genet. 2015;24(18):5126-41.

25. Ning Z, Williams JM, Kumari R, Baranov PV, Moore T. Opposite expression patterns of Spry3 and p75NTR in cerebellar Vermis suggest a male-specific mechanism of autism pathogenesis. Front Psychiatry. 2019;10:416.

26. MacDonald JR, Ziman R, Yuen RK, Feuk L, Scherer SW. The database of genomic variants: a curated collection of structural variation in the human genome. Nucleic Acids Res. 2014;42(Database issue):D986-92.

27. Firth HV, Richards SM, Bevan AP, Clayton S, Corpas M, Rajan D, et al. DECIPHER: database of chromosomal imbalance and phenotype in humans using Ensembl resources. Am J Hum Genet. 2009;84(4):524-33.

28. Rehm HL, Berg JS, Brooks LD, Bustamante CD, Evans JP, Landrum MJ, et al. ClinGen--the clinical genome resource. N Engl J Med. 2015;372(23):2235-42.

29. Harewood L, Fraser P. The impact of chromosomal rearrangements on regulation of gene expression. Hum Mol Genet. 2014;23(R1):R76-82.

\section{Publisher's Note}

Springer Nature remains neutral with regard to jurisdictional claims in published maps and institutional affiliations.

Ready to submit your research? Choose BMC and benefit from:

- fast, convenient online submission

- thorough peer review by experienced researchers in your field

- rapid publication on acceptance

- support for research data, including large and complex data types

- gold Open Access which fosters wider collaboration and increased citations

- maximum visibility for your research: over $100 \mathrm{M}$ website views per year

At BMC, research is always in progress.

Learn more biomedcentral.com/submission 